\title{
IS TUBERCULOSIS A FAMILIAL COMMUNICABLE DISEASE? HIGH TIME TO STRENGTHEN CONTACT SCREENING
}

\author{
TIMSI JAIN, RAJA JD, RUMA DUTTA*, SIVAPRAKASAM P, JAYASHRI D, GOMATHY PARASURAMAN, \\ YOGESH MOHAN
}

Department of Community Medicine, Saveetha Medical College, Chennai - 602 105, Tamil Nadu, India. Email: rumadr14@gmail.com

Received: 18 October 2017, Revised and Accepted: 16 November 2017

\begin{abstract}
Pulmonary tuberculosis (TB) is a highly communicable disease and represents a serious public health problem. In the absence of active case detection and early diagnosis among close contacts of a known TB patient, the family members are at high risk of developing the disease and are the potential source of spread of the disease in the community. Here, we discuss a case of pulmonary TB which stresses on the importance and urgent need for screening all household contacts and for early diagnosis and treatment of all cases and susceptible contacts.
\end{abstract}

Keywords: Pulmonary tuberculosis, Household contacts, Case detection, Early diagnosis, Treatment.

(C) 2018 The Authors. Published by Innovare Academic Sciences Pvt Ltd. This is an open access article under the CC BY license (http://creativecommons. org/licenses/by/4. 0/) DOI: http://dx.doi.org/10.22159/ajpcr.2018.v11i2.23182

\section{INTRODUCTION}

Tuberculosis (TB) still continues to be India's severest health crisis despite several control measures [1,2]. TB kills an estimated 480,000 Indians every year and more than 1400 every day. India also has more than a million "missing" cases every year that are not notified and most remain either undiagnosed or unaccountable and inadequately diagnosed [3]. Here, we discuss a case of pulmonary TB which stresses on the importance and need for screening of all household contacts, early diagnosis, and treatment of all cases and susceptible contacts.

\section{CASE REPORT}

Mr. Munusamy, aged 59 years, a farmer by occupation, developed fever with cough in May 2017. He is a chronic alcoholic, smoker, and tobacco chewer. He visited Kanchipuram Government District Hospital for consultation and was diagnosed with pulmonary TB. The patient was given anti-TB medicines for 1 week and was advised to come back for review and for continuation of treatment. He took the medicines only for 3 alternate days, following which he said he had developed dizziness and loss of appetite. He was not able to tolerate the symptoms and therefore refused to further continue the treatment.

The nurse from the government hospital called and explained the patient about the dreadful course of the disease and asked him to come back immediately for continuing and completing the full course of treatment. However, he never responded. In spite of several home visits later and counseling by the health worker, the patient refused to continue the treatment any further.

After 5 months of absence of treatment, patient's symptoms worsened, and on the night of September $11^{\text {th }}$ 2017, patient was admitted to Saveetha Medical College Hospital Emergency ward with complaints of severe breathlessness, fever, and cough. He was shifted initially to medicine ward where he was started on treatment for anemia, acute kidney failurem and skin problems. His sputum was found to be positive for acid-fast bacilli and was transferred to TB ward for further treatment and management on September $15^{\text {th }} 2017$. He was put on modified anti-tuberculosis treatment (ATT) regimen due to his other comorbid conditions.
On further inquiry, the patient gave a positive family history of TB.

\section{FAMILY HISTORY}

In 2011, (6 years back), Mr. Munusamy's first son Mr. Madan, now 29 years, was diagnosed with TB in Maduramangalam Government Community Health Center (CHC). He was started on ATT for 6 months. He took the treatment only for 3 months and then stopped it by himself once the symptoms subsided, and as he felt, he was apparently healthy. However, after 1 month without treatment, he developed severe cough. He went to the CHC where he was again put on ATT and he completed the full course.

In 2014 (3 years back), Mr. Munusamy's second son Mr. Mannavan, now 27 years, developed cough and fever. He was also diagnosed as having pulmonary TB. He was also put on 6 months ATT and he completed the full course.

Patient's family also includes his wife Mrs. Thulukanam aged 48 years and youngest son Mr. Kannan aged 19 years, who are yet to be screened.

\section{DISCUSSION}

The possible reasons in Mr. Munusamy for getting the disease from the close household contacts (his own sons) may be:

1. Failure to diagnose early/failure in the screening of the household contacts: On both occasions, when his two sons got diagnosed and treated for TB in the past 6 years, none of the other family members including the patient were screened for TB.

2. Failure to complete treatment/regular treatment: The first son Mr. Madan stopped taking treatment after 3 months.

3. The family contacts were not kept under surveillance for nearly 3 years.

4. Failure in follow-up: Mr. Munusamy was diagnosed earlier in May 2017 , took treatment for a week and then discontinued, he received some phone calls and home visits from the TB worker who failed to convince him to continue the treatment.

Currently, under the Revised National Tuberculosis Control Program, the household contacts and close contacts of newly diagnosed case of TB are advised to report to the health facility at the earliest if they have persistent cough for more than 2 weeks [4]. Nair et al. suggested that active screening among household contacts is an effective way to improve TB case detection [5]. 
However, so far, the case detection for TB has largely been passive under the program. There is a requirement for moving toward TB elimination by integrating the four strategic pillars, i.e., "detect - treat - prevent - build." "Detection" includes systematic screening of highrisk populations with the priority for immediate household contacts, "treatment" includes preventing the loss of TB cases in the cascade of care with support systems, "prevent" includes preventing the emergence of TB in susceptible populations by providing treatment for latent TB infection for contacts of people with confirmed TB, and "build" includes building supportive structures for surveillance [3].

\section{CONCLUSION}

Early case detection and treatment of the close contacts at the family and community level have to be initiated and strengthened. Symptomatic people must be actively identified, diagnosed, and put on regular treatment and also to ensure good bacillus calmette-guérin vaccine coverage in the community.

\section{REFERENCES}

1. Shaji J, Shaikh M. Drug-resistant tuberculosis: Recent approach in polymer based nanomedicine. Int J Pharm Pharm Sci 2016;8:1-6.

2. De Moura AC, Mosegui GB, De Mello Vianna CM, Cordeiro BC. Costeffectiveness analysis of directly observed therapy for tuberculosis and its expansion in Rio de Janeiro. Int J Pharm Pharm Sci 2017;9:171-5.

3. Ministry of Health and Family Welfare. Central TB Division; Ministry of Health and Family Welfare; Government of India, National Strategic Plan for Tuberculosis Elimination, 2017-2025, Program RNTCP. New Delhi, India: RNTCP; 2017. Available from: http://www.tbcindia. gov.in/WriteReadData/NSP\%20Draft\%2020.02.2017\%201.pdf. [Last accessed on 2017 Oct 12].

4. Kishore J. National Health Programs of India: National Policies and Legislations Related to Health. $11^{\text {th }}$ ed. New Delhi: Century Publication; 2014. p. 270-1.

5. Nair D, Rajshekhar N, Klinton JS, Watson B, Velayutham B, Tripathy JP, et al. Household contact screening and yield of tuberculosis cases-a clinic based study in Chennai, South India. PLoS One 2016;11:1-10. 